\title{
PROBABILISTIC ANALYSIS OF RESISTANCE DEGRADATION UNDER CORROSION
}

To observe the behaviour and resistance of steel bridges with the orthotropic plate decks, the nonlinear finite probabilistic model in the ANSYS software environment was developed using software support module PDS. Random variables were described by means of parameters of probability density function according to data determined experimentally. The model takes also into account the geometrical and material nonlinearities of the structure. The major aim of the paper is to obtain the corrosion effects influence on the resistance of this structural system. Therefore the time variant loss of member resistance was computed based on selected corrosion models.

Keywords: prediction of ultimate strength, time - dependent corrosion effects, stochastic modelling using FEM software.

\section{Introduction}

Stiffened plated structural elements are the main and very important parts of the box girder bridge structures or the bridge structures with ballast bed. Their structural integrity has direct implications on the safety and reliability. Accurate prediction of the ultimate strength of stiffened plated elements is a very important task for engineers. There has been conducted extensive work in predicting the compressive strength of rectangular plated elements since 1970s. However, much less work has been devoted to the probabilistic formulation of their ultimate strength. An adequate probabilistic model of the ultimate strength is necessary to develop for structural reliability assessment of those types of structures due to significant uncertainties of the initial performance, effects of deterioration and because of the stochastic nature of all factors affecting the resistance (structural geometric characteristics, material properties).

The effort was focused on the determination of stress state of compression orthotropic decks creating the upper flanges of bridges with ballast beds. Their stress state is significantly influenced by the interaction of buckling, shear lag and effect of transverse load due to traffic action resulting from the deck performance. Concurrently, the geometrical and material nonlinearities should be taken into account. To analyze the behaviour and resistance of the bridge orthotropic deck subjected to traffic action, the nonlinear computational model of the railway bridge with the ballast bed was developed using software ANSYS.

Nevertheless, the actual structural member resistance could be changed by various factors like degradation of materials due to aggressive environment. In general, deteriorating structures are maintained in accordance with their condition states. Because of limited available resources, incorrect maintenance decisions and although many quality corrosion protection systems are available at present, phenomena of corrosion as the basic and most important degradation effect is significant all the time.

Effects of this degradation cause material loss leading to the reduction of structural resistance. Corrosion effects influencing member resistance can be obtained by means of a structural model based on some corrosion models. Then, corrosion effects could be expressed in the form of the time variant loss of the resistance. The parametric study of simulation of corrosion effect was realized to observe the variation of the bridge ultimate strength within the bridge service lifetime resulting from the generalized corrosion of the bridge stiffened deck plate.

\section{Structural model}

Two numerical finite calculation models were developed - the deterministic model and the probabilistic one. To determine the resistance of compression stiffened flange, the orthotropic plate was necessary to model using thin shell elements with the adequate finite element mesh allowing for the effect of plasticization and large deflections. The developed model was calibrated using the results of experimental analysis with emphasis on the real structural behaviour.

A bridge structure was modeled using shell finite elements of SHELL 181. Von Misses isotropic nonlinear plastic material model with bilinear hardening was applied to describe material characteristics given by the bilinear stress - strain diagram with the elasticity module $E=210 \mathrm{GPa}$, hardening module of $E / 100$ and yield strength of $f_{y}=285.91 \mathrm{MPa}$ corresponding to the measured and

\footnotetext{
* Josef Vican, Marian Sykora

Department of Structures and Bridges, Faculty of Civil Engineering, University of Zilina, Slovakia, E-mail: vican@fstav.uniza.sk
} 
evaluated actual mean value of the yield strength of the real bridge structure.

Due to absence of measured initial imperfections, the standard equivalent geometrical initial imperfection in the form of sinusoidal surface was incorporated into the calculation model. The transverse displacement fields of imperfect plates are normally represented by a double Fourier series. For generally used ratios of plate dimensions, following equation was considered for modeling the initial imperfections

$$
w_{0}=f_{0} \sin \pi x / a \sin \pi y / b,
$$

where $f_{0}$ is the value of initial plate bow amplitude, $a$ and $b$ are the plate length and width respectively.

The amplitude of the longitudinal stiffener initial bow was considered by the value of $a / 400$ in accordance with EN 1993-1-5 and the initial bow of the deck sheet in transversal direction between longitudinal stiffeners was given in the form of "hungry horse" with the amplitude $b / 200$.

The resulting shape of the global bridge deck imperfection shape can be seen in Fig. 1.

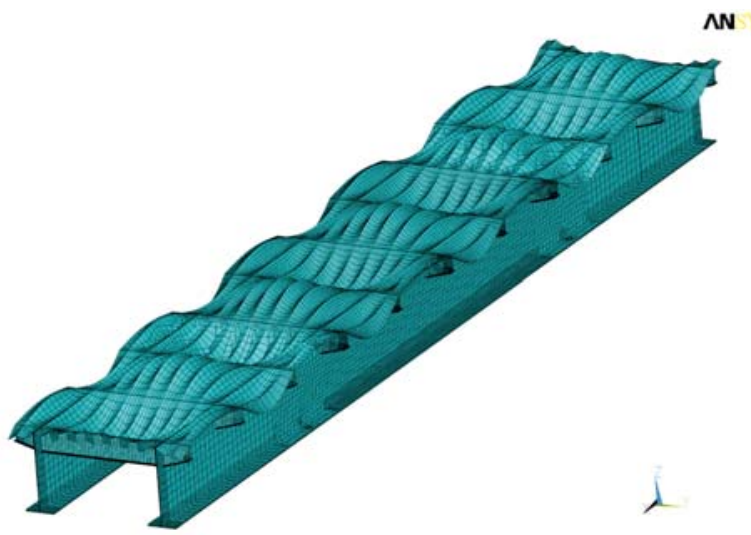

Fig. 1 Deterministic finite element model of orthotropic plate deck shape of initial deformation (multiplied 100 times) with finite element mesh.
The probabilistic model was developed using deterministic one and software support module PDS (Probabilistic Design System) allowing for direct connection between FEM analysis and methods of the probability analysis. Based on the parameters of material characteristics as well as other random variable input values and their statistical models, PDS module enables to generate files of random variables and to calculate required probabilities. Using sensitivity analysis, the effect of input parameters on the structural resistance could be determined achieving the reliability optimal level.

Random character of individual values was considered in accordance with the Gaussian random process. Random variables were described by means of parameters of probability density distribution according to data determined experimentally. The calculation was carried out using LHS simulation method for 40 steps of the data dispersion. The nonlinear calculation ran in every step determining random output parameters in the form of stresses and deformations of girder bottom flanges in experimentally measured places (see Fig. 2). Concurrently, in frame of probabilistic calculation, the effect of random input variables on the stress and deformation intensity was evaluated by means of stochastic sensitivity analysis using Spearman correlation coefficients. All variables were taken into account as parameters influencing sensitivity and the resulting effect was introduced using the percent expression.

\section{Corrosion modelling}

Corrosion of the plate deck due to environmental conditions was taken into account. Two cases of the bridge deck corrosion were considered. Firstly, the corrosion was supposed to be acting on the lower part of bridge deck only under the assumption that the deck insulation would be serving during the whole bridge lifetime. Secondly, the corrosion was considered to act on the lower and also upper part of the bridge deck, so that the bridge insulation was not perfect during the whole bridge lifetime. Due to absence of the actual corrosion model of this structural model, known corrosion prediction models were used for corrosion modeling of the lower part of the bridge deck. Therefore, general models of AkgulFrangopol [1] and of Qin - Cui [3] were used.

Input random variable specifications

Table 1

\begin{tabular}{|c|c|l|c|c|c|}
\hline No. & & Name of parameterType of distribution & Type of distribution & Mean value & Cov. \\
\hline 1 & $T P L$ & Thickness of plate & Normal & 14.076 & 0.15500 \\
\hline 2 & TFHN & Thickness of main girder flange & Normal & 50.070 & 0.21800 \\
\hline 3 & $T F P R$ & Thickness of cross beam flange & Normal & 15.561 & 0.14300 \\
\hline 4 & $T V Y S T$ & Thickness of stiffener & Normal & 25.310 & 0.28400 \\
\hline 5 & $T W H N$ & Thickness of main girder web & Normal & 14.272 & 0.17600 \\
\hline 6 & VYSKAVYST & Stiffener height & Log - normal & 248.89 & 1.80500 \\
\hline 7 & $E X I$ & Elasticity modulus & Log - normal & 285.91 & 8400.0 \\
\hline 8 & $F Y 1$ & Yield strength & & & 16.09000 \\
\hline
\end{tabular}


The corrosion losses were determined using following relations expressing the mean value and standard deviation in the case of Frangopol model

$$
\begin{aligned}
& \mu_{d c o o r}=0.03207 t^{0.5}, \\
& \sigma_{d c o r r}=0.00289 t^{0.045},
\end{aligned}
$$

and in the case of Qin-Cui model

$$
\begin{aligned}
& \mu_{d c o r r}=1.67\left[1-\exp (-t / 9.15)^{1.97}\right], \\
& \sigma_{d c o r r}=0.0674\left[1-\exp (-t / 0.181)^{0.0294}\right],
\end{aligned}
$$

where $t$ is time in years.

Corrosion effect was taken into account by means of thickness reduction dcorr calculated according to the above mentioned probability models using following relation

$$
t_{p l, r e d}=t_{p l}-d_{c o r r}
$$

where $t_{p l}$ is the plate thickness without corrosion effects.

\section{Numerical analysis of corrosion influence on the resistance}

Numerical analysis was accomplished using the calculation model described in chapter 2. The calculation model developed in the software environment ANSYS consisted of 56472 nodes, 45163

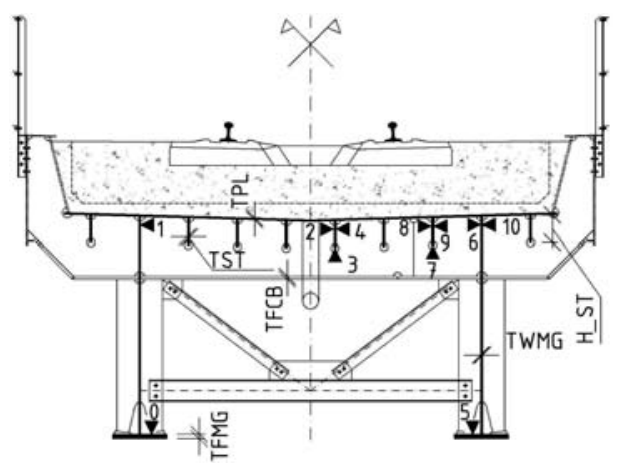

Fig. 2 Cross section of bridge with ballast bed shell elements and 44 beam elements. The traffic action was modeled as the uniformly distributed load, due to load distribution through the ballast bed under railway sleepers in the slope of 4:1 according to the EN 1991-2.

Firstly, the deterministic geometric and material nonlinear analysis of the imperfect structure (GMNIA) using average crosssectional characteristics was accomplished. Then using incremental analysis, the resistance of bridge structure was determined under assumption that the limit state of the structure was declared by the structural collapse represented by the maximum load attainment in numerical calculations. Also the stresses were controlled to observe the state when the bridge deck would be in an elastic-plastic state and the plastic strain could achieve the value of $2 \varepsilon_{y}$ ( $\varepsilon_{y}$ corresponds to the steel yield strength).

Secondly, the stochastic analysis was realized. The results of this analysis (the mean values and standard deviations) are shown in Table 2 compared to the deterministic one. Some outputs of this analysis can be seen in Figs. 5-7.

In this study, the effect of random input variables on the stress and deformation intensity was evaluated by means of stochastic sensitivity analysis using Spearman correlation coefficients. All variables were taken into account as parameters influencing sensitivity and the resulting effect is introduced in percent expression. Because of the limited paper size, there are presented only the results of stresses at the midspan of longitudinal stiffener. Nevertheless, it can be seen from the Figures that the importance level of the stiffener cross-sectional characteristics is higher in the case of elastic range. In the case of collapse, the greatest importance level was achieved by the yield strength. These results were confirmed by the matrix of the rank correlation coefficient.

The time variant analyses were the third and fourth analysis type, by which the time dependent effects of the environmental action in the form of corrosion were taken into account. For both above mentioned prediction models of corrosion losses, the timedependent development of resistance within the design working life of 100 years was computed. The resistance was computed in discrete time points with time step of 5 years until 25 years and then was used the time step of 25 years. The time-dependent development of the maximum applied load on the structure (at the collapse) can be seen in Fig. 6 and the time-dependent development of minimum and maximum stresses in the middle of the bridge structure span can be seen in Fig. 7 (for the same load intensity

Comparison of obtained stresses (the load intensity $250 \mathrm{kN} \cdot \mathrm{m}^{-2}$ ).

Table 2

\begin{tabular}{|l|c|c|c|c|c|c|c|c|}
\hline $\begin{array}{l}\text { Stress [MPa] } \\
\text { Results from }\end{array}$ & $\sigma_{0}$ & $\sigma_{1}$ & $\sigma_{2}$ & $\sigma_{3}$ & $\sigma_{5}$ & $\sigma_{6}$ & $\sigma_{7}$ & $\sigma_{8}$ \\
\hline Design calculation EN1993-1-5 & 350.94 & -277.59 & -267.47 & -105.08 & 350.94 & -277.59 & -93.36 & -191.83 \\
\hline ANSYS - deterministic & 287.32 & -258.79 & -271.28 & -108.53 & 290.28 & -264.54 & -79.63 & -157.39 \\
\hline ANSYS - stochastic - mean & 287.48 & -259.31 & -272.89 & -106.37 & 290.35 & -265.54 & -81.82 & -158.70 \\
\hline -standard deviation & 15.665 & 8.226 & 7.265 & 14.708 & 15.121 & 8.713 & 3.110 & 6.938 \\
\hline
\end{tabular}




\section{caMMNICOIIONS}

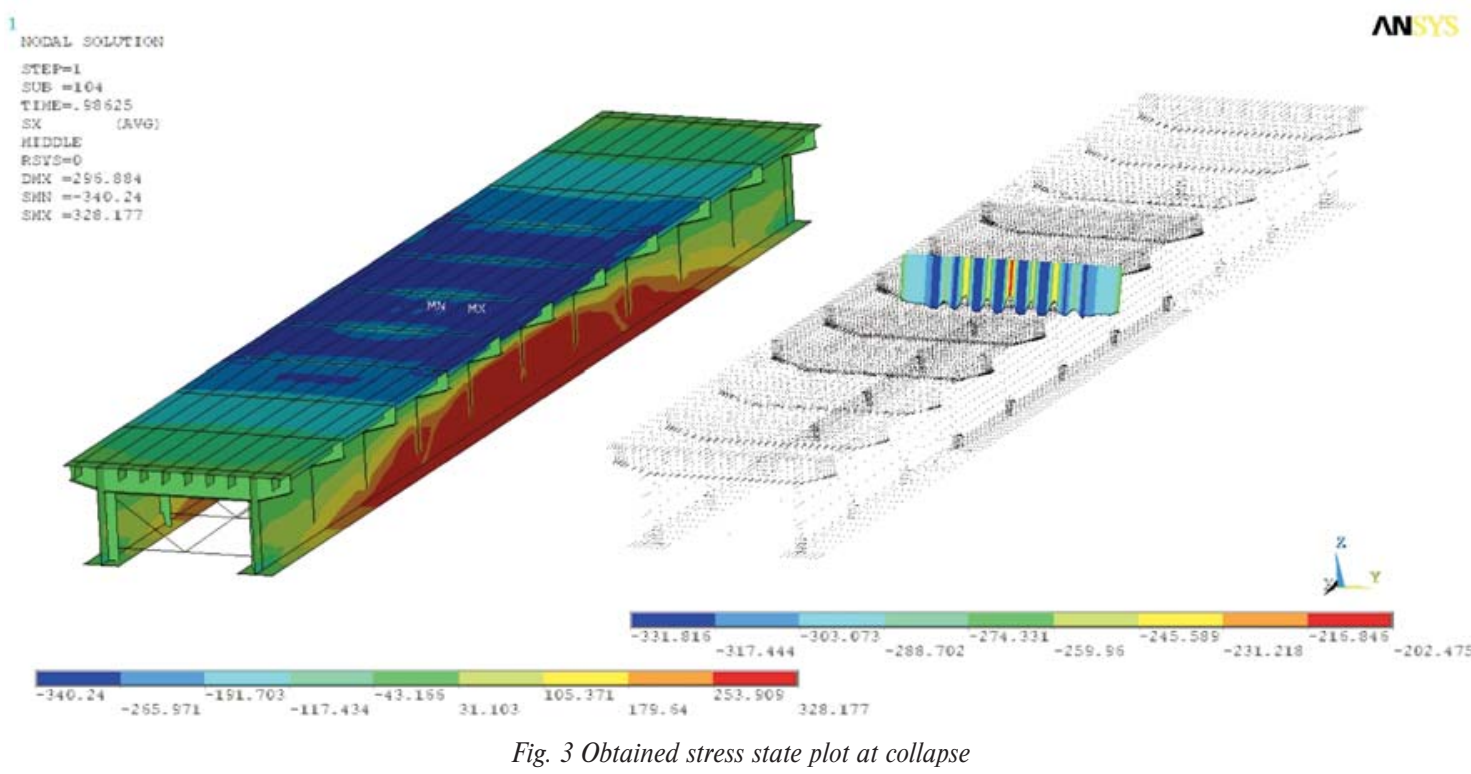

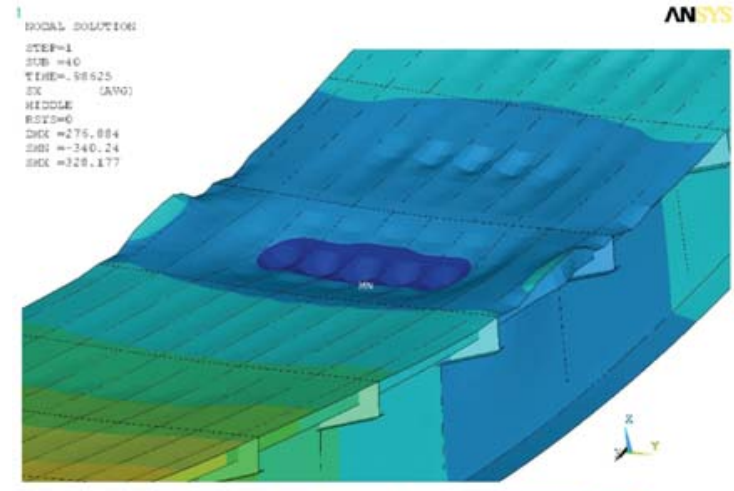

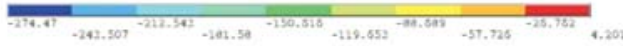

Fig. 4 Deformed deck shape at collapse

Cumulative Distribution Function
Reguit Set PDS PARFA

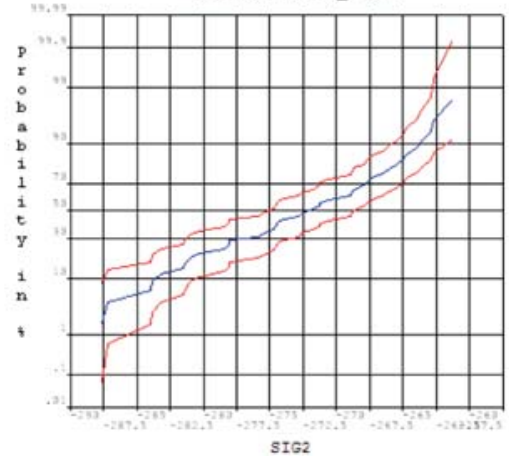

$\mathbf{N}$

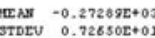

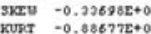

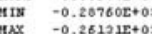

Contidence Lisit

Fig. 6 Cumulative distribution function of the sigma 2
Rank-Order Correlation Sensitivities

$\mathbf{N}$

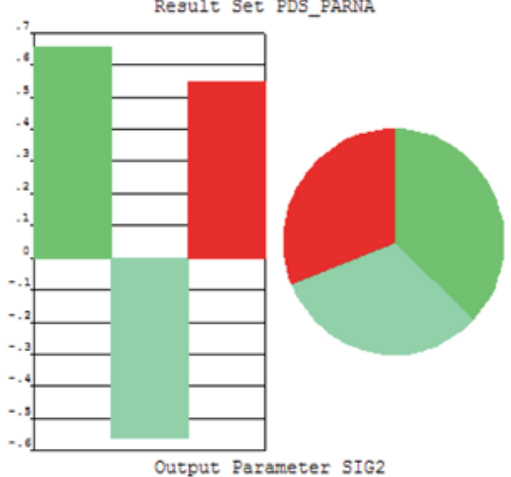

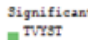

INTs

Tr2

Insigniticans:

Trmas

rawst

${ }_{\mathrm{F}}^{\mathrm{Ex} 1}$

Sigrifiteance level:
2.s00t

Fig. 5 Sensitivity plot for sigma 2

Histogram

Result Set PDS PARNA

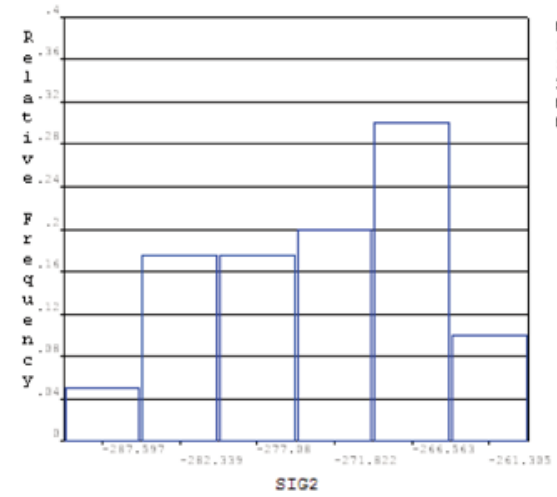

NN

IIIAS $-0.27289 E+03$

$\begin{array}{lr}\text { STDEV } & 0.72650 \mathrm{~T}+01 \\ \text { SKIT } & -0.23698 \mathrm{E}+00\end{array}$

$\begin{array}{ll}\mathrm{MIM} & -0.28760 \mathrm{E}+03 \\ \mathrm{MAX} & -0.26131 \mathrm{E}+03\end{array}$ 


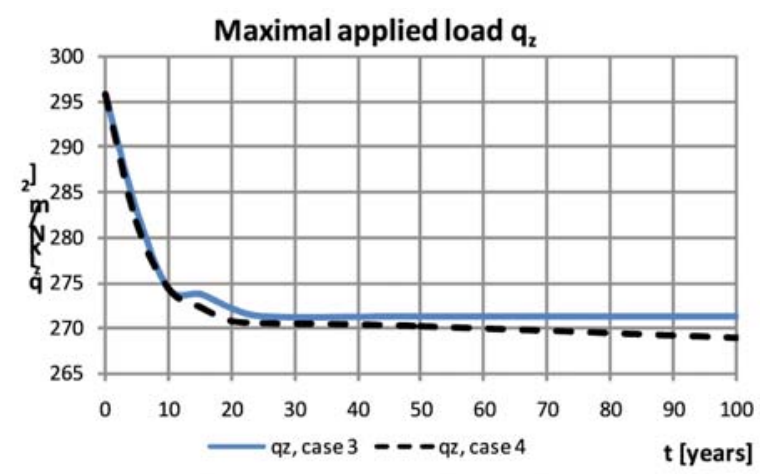

Fig. 6 Time-dependent development of maximal applied load on the structure

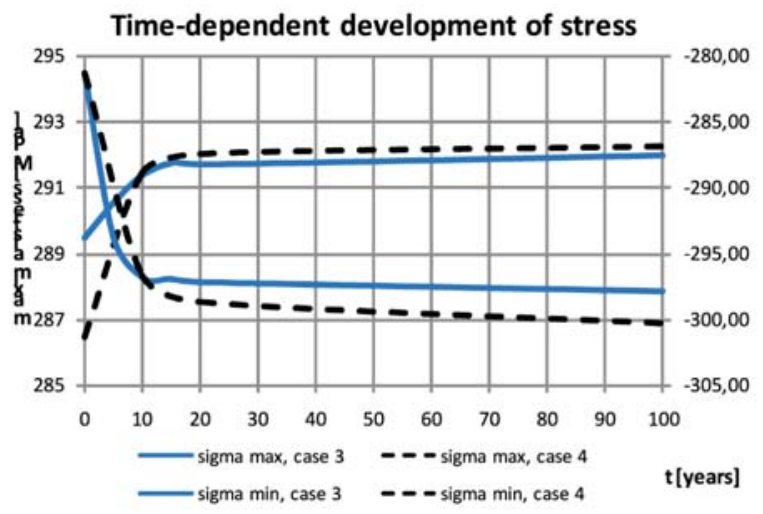

Fig. 7 Time-dependent development of peaks of stresses

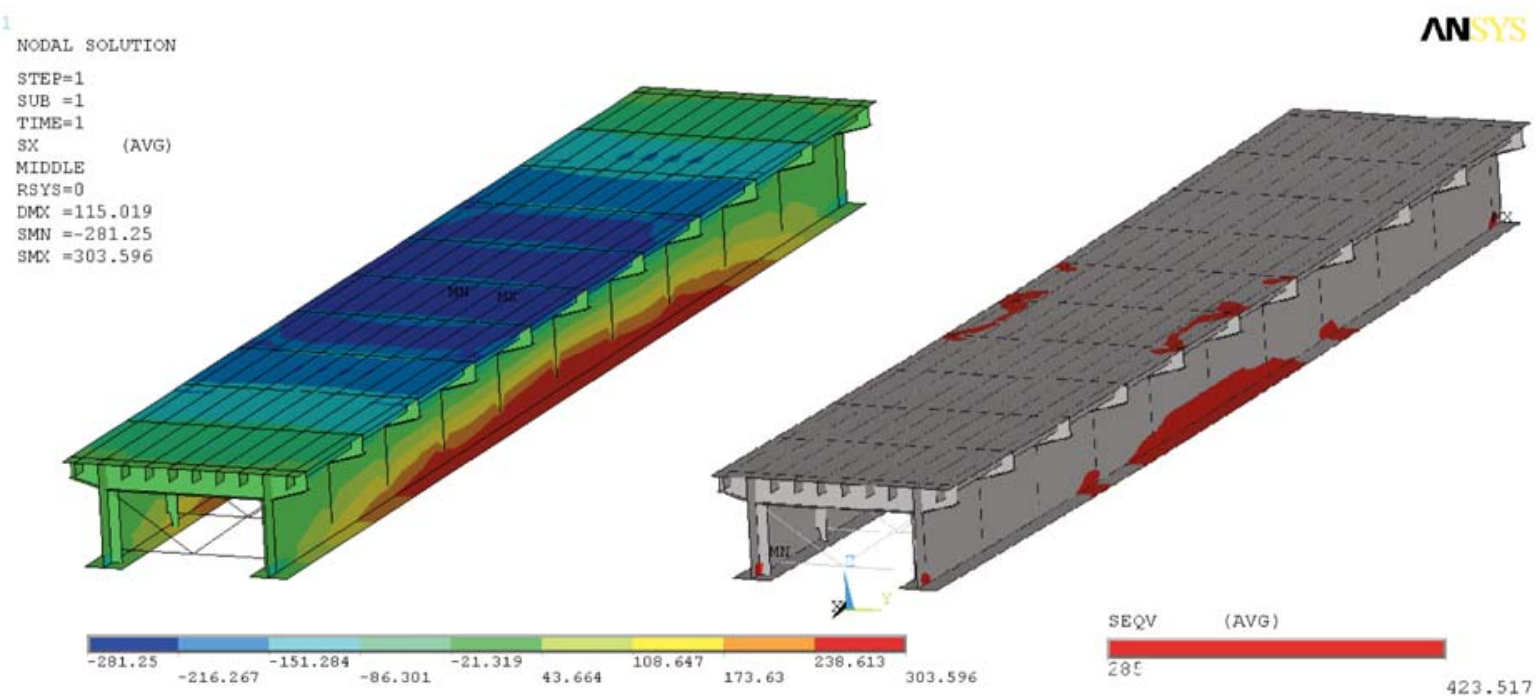

Fig. 8 Obtained stress state plot in the time $=0$ years, load intensity $=250 \mathrm{kN} / \mathrm{m}^{2}$

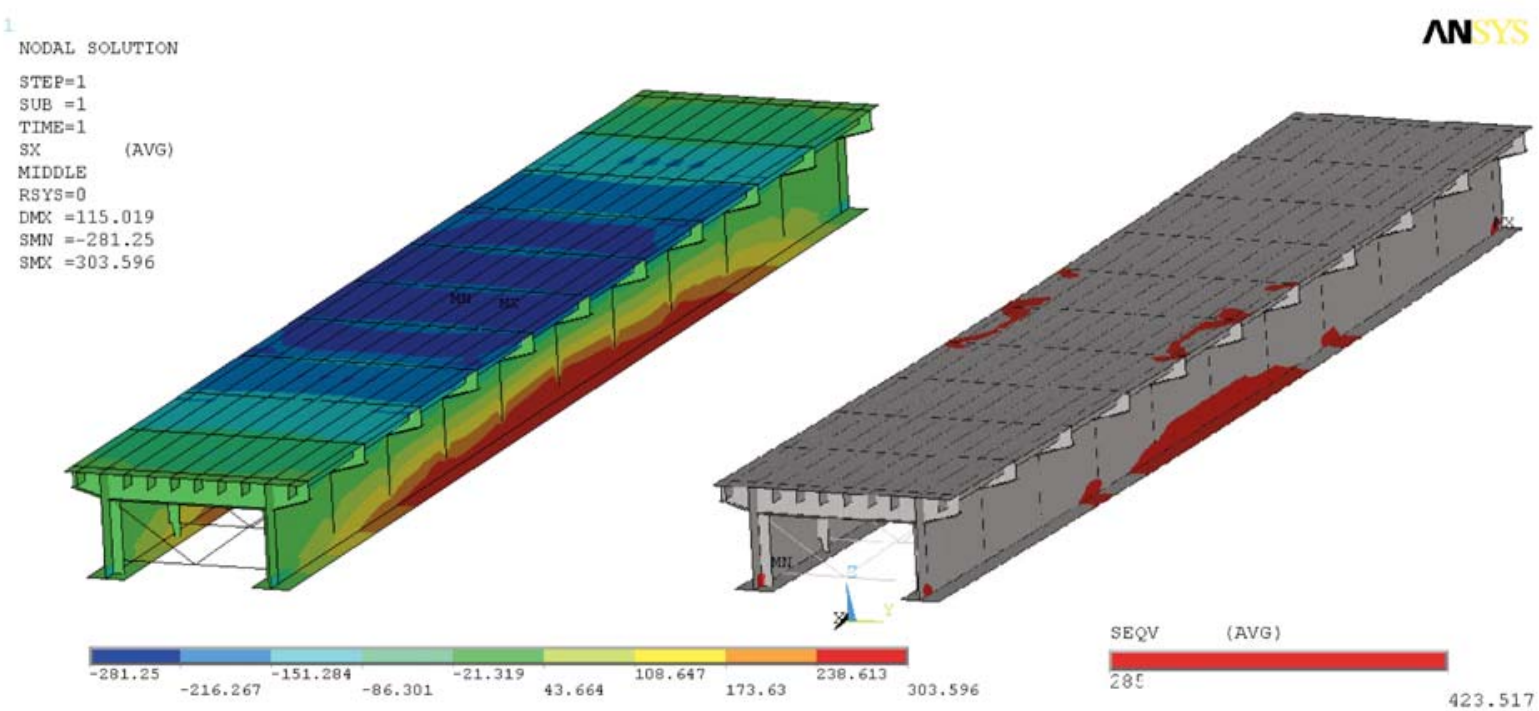

Fig. 9 Obtained stress state plot in the time $=100$ years, load intensity $=250 \mathrm{kN} / \mathrm{m}^{2}$. 
of $250 \mathrm{kN} \cdot \mathrm{m}^{-2}$ ). From Figs. 6 and 7 it can be seen that there is a little difference between the values of both cases, if the corrosion affect only the bottom side of bridge deck or both sides (also corrosion under ballast bed).

\section{Conclusion}

The paper presents specifications of the real behaviour of the bridge orthotropic plated deck with the ballast bed. The probability distribution of the ultimate strength of the imperfect bridge deck structure under out-of-plane load and axial compression resulting from global bending was evaluated in dependence on several random variables and assessed by a nonlinear finite element analysis.

The bridge deck resistance is significantly influenced by the corrosion degradation and therefore the corrosion effects should be taken into account for a structural design. On other hand, the bridge deck resistance is ensured by structural redundancy accord- ing to the Slovak standard at the present time. Although the corrosion effect means the structural resistance decrease by about $11 \%$, it is controversial to increase the deck plate thickness according to the recommendation in EN 1993-1-1, whereas the difference of the corrosion effect in cases 3 and 4 respectively is not significant.

Another parametric study has to be carried out for various deck plates and longitudinal stiffener slenderness using stochastic analysis to obtain more results for more sophisticated conclusion analysis. Except of that, the research of corrosion processes under the insulation of the bridge deck should be conducted to obtain the actual model of corrosion losses prediction.

\section{Acknowledgement}

The paper presents results of the project implementation: "Centre of Excellence in Transport Engineering" (ITMS: 26220120027) supported by the Research \& Development Operational Programme funded by the ERDF.

\section{References}

[1] AKGUl, F., FRANGOPOL, D. M.: Lifetime Performance Analysis of Existing Steel Girder Bridge Superstructures. Journal of Structural Engineering, v. 130, No. 12, pp. 1875-1888.

[2] BUCHER, CH., HINTZE, D., ROSS, D.: Advanced Analysis of Structural Reliability Using Commercial FE-codes. EC-COMAS, Barcelona, 2000

[3] QIN S., CUI W.: Effect of Corrosion Models on the Time-dependent Reliability of Steel Plated Elements. Marine Structures, Elsevier, 2003

[4] SYKORA, M., VICAN, J.: Numerical and Experimental Analysis of Steel Orthotropic Plate Deck Stress State. XVIII. Russian-SlovakPolish seminar Theoretical foundation of civil engineering. Warszawa: Oficyna Wydawnicza Politechniki Warszawskiej, 2009.

[5] SERTLER, H., VICAN, J.: The Real Behaviour of Steel Railway Bridges. Zilina: ES VSDS, 1995 (in Czech).

[6] EN 1993-1-5: Design of Steel Structures - Part 1-5: Plated Structural Elements. CEN: Brussels, 2003.

[7] ANSYS Reference manual: Release 10.0 Documentation for ANSYS. 